\title{
Breves Considerações Sobre a Criminalidade Escrava Segundo o "Livro de Sentenciados" da Casa de Correção de Porto Alegre (1874-1900)*
}

\section{Marília Conforto**}

O passado colonial brasileiro teve a maior parte de sua economia assentada no braço escravo. A este sistema, o negro respondeu com a fuga, o suicídio, o quilombo, a insurreição e a criminalidade. $O$ museu da Academia de Polícia Civil de Porto Alegre possui em seu acervo doze livros denominados "Livros de Sentenciados" (LS). O volume que abrange o período 1874-1900 servia, segundo seu termo de abertura, "para assentamento dos presos sentenciados reclusos na Casa de Correção de Porto Alegre". O estado de conservação do livro é excelente e permite uma fácil cópia das sentenças. $\mathrm{Na}$ transcrição, conservamos a grafia das palavras.

A Casa de Correção de Porto Alegre, também chamada de "Cadeião", estava localizada na Volta do Gazômetro. Foi criada pelo decreto $\mathrm{n}^{2} 2$, da Assembléia Provincial, de 1835, que determinava que Porto Alegre e a Vila de São Francisco de Paula de Pelotas fossem os locais escolhidos para a construção da Casa de Correção. Elas deveriam estar situadas, se possível, nas proximidades de rios navegáveis e de águas potáveis. Caberia ao Presidente da Província a escolha dos terrenos e, na falta de terrenos de propriedade das Câmaras Municipais ou da massa de bens da Província, ele procederia a sua aquisição por compra. A capacidade dos edifícios deveria ser suficiente para o recolhimento e

* Agradecemos a leitura do Professor Dr. Mário Maestri.

* *Mestranda em História da PUCRS. 
trabalho de "todos os condenados da Província". Em cada Casa de Correção existiria uma escola para a alfabetização dos condenados. Ficava o Governo Provincial encarregado de organizar o Regimento para sua administração. As Câmaras Municipais eram responsáveis pelas oficinas de "marceneiro", "alfaiate", "sapateiro" e outras (cf. Anexo II).

A Revolução Farroupilha retardou a construção da Casa de Correção. No ano de 1851, o vice-presidente da Província em exercício, Luiz Alves de Oliveira Belo, sancionou a Lei no 234 que determinava um capital de 20:000\$000 rs para a construção da Casa de Correção. Três anos mais tarde, foi concluída a primeira secção da cadeia, pelo valor de 25:000\$000 rs. Ficando os gastos da obra total da primeira seç̧ão em 150:000\$000. A 28 de fevereiro de 1855, foram removidos, para as novas instalações, 195 presos que estavam nos porões do $13^{\circ}$ Batalhão, então servindo de Cadeia Provincial. ${ }^{1}$

Em 1856, para manter uma população carceraria de 200 presos, foram gastos 20:000\$000 rs. Os presos estavam condenados a diversas penas. Em geral, elas constituíam-se de prisão com trabalhos. No ano de 1864, o presidente da Província, Espiridião Eloy de Barros Pimentel, em relatório apresentado à $11^{\text {a }}$ Legislatura da Assembléia Provincial, fez alusão à insalubridade e à falta de segurança da Casa de Correção. Ele determinou a conclusão das obras dos paredões que circulavam o edifício e que há muito se achavam paralisadas.

O "Cadeião" foi demolido na gestão do prefeito Célio Marques Fernandes. De acordo com notícias dos jornais, o Cadeião teve, em cinco anos, três solenidades de demolição. Ela efetuou-se, finalmente, sob o comando do engenheiro João Dib e foi realizada por operários da Secretaria Municipal de Obras e Viação. Foram utilizados tratores e dinamite. A campanha de demolição foi iniciada em 1962, quando José Loureiro da Silva lançou o slogan: "Precisamos desalgemar o Guaíba".

Outros motivos também teriam levado à demolição da Casa de Correção. Os jornalistas que faziam a cobertura dos acontecimentos narraram as atrocidades, os maus tratos e o péssimo atendimento a que eram submetidos os detentos. Era igualmente alta a criminalidade entre eles. Mortes, incêndios, revoltas assinalaram a crônica policial da época. Quando ficou pronta a penitenciária da Chácara das Bananeiras, em 1962, foram para lá removidos 600 presos. Então os jornalistas propuseram a demolição do prédio. A administração municipal tinha outros 
motivos. O Plano Diretor, de 1959, renovado em 1963, deliberou reconstruir todo o sistema urbanístico da Volta da Cadeia. ${ }^{3}$

\section{Sentenças da Casa de Correção de Porto Alegre}

Pesquisamos dez sentenças de escravos, assentadas no primeiro volume do Livro de Sentenciados da Casa de Correção. Os crimes sentenciados, todos homicídios, foram cometidos entre 1873 e 1886. Para esta periodização, definimos a data da prisão preventiva. Já que no texto das sentenças não consta o ano em que o crime foi cometido (cf. Anexo I, Tab. III). Segundo os anos, os crimes cometidos por homens escravizados estavam assim divididos:

TABELA 1

Freqüência anual dos crimes

\begin{tabular}{lc}
\hline Ano & Detenção \\
\hline 1873 & 1 \\
1877 & 1 \\
1881 & 2 \\
1882 & 3 \\
1886 & 1 \\
1887 & 2 \\
\hline TOTAL & 10 \\
\hline
\end{tabular}

FONTE: LS - 1874-1900.

As penas estabelecidas para os crimes variavam: quatro crimes, com 24 anos de "prisão celular"; 4 um crime, com 30 anos de "prisão celular"; três crimes, com "galés perpétuas" e, dois crimes, com pena de morte transformadas em "galés perpétuas". Na leitura das sentenças, percebemos que, em alguns casos, as penas foram modificadas. Lembramos o decreto de 1876 , que reformou a pena de morte em "galés perpétuas". Mais tarde, com a introdução do novo Código Penal republicano, as penas de "galés perpétuas" deixaram de existir e a "prisão com ferros" deu lugar à "prisão com trabalho".

As custas dos processos eram pagar pelos senhores dos sentenciados. No relativo ao local onde foram cometidos os crimes, temos: 
TABELA 2

Localidades onde foram cometidos os crimes

\begin{tabular}{lc}
\hline Cidade & $N^{\circ}$ de Crimes \\
\hline Pelotas & 5 \\
Santa Vitória do Palmar & 2 \\
Santo Antônio da Patrulha & 2 \\
Jaguarão & 1 \\
\hline TOTAL & 10 \\
\hline
\end{tabular}

FONTE: LS - 1874-1900.

A maior incidência verifica-se em Pelotas, zona de charqueada, onde tínhamos grande concentração de escravos. As idades dos cativos variavam entre 21 e 60 anos: cinco, tinham de 21 a 29 anos; dois, 34 e 35 anos; dois, 42, 45 anos e um 60 anos. Todos eram negros e analfabetos. Nove eram solteiros e um víúvo. Os escravos não eram altos. A média de suas alturas era de 1,49. O escravo mais alto tinha 1,71 e o mais baixo, 1,25 (cf. Anexo I, Tab. II).

Todos os escravos eram nacionais.

\begin{tabular}{lc}
\multicolumn{2}{c}{ TABELA 3 } \\
& Naturalidade escrava \\
\hline Cidade & $N^{\circ}$ de Escravos \\
\hline Rio Grande do Sul & 7 \\
Bahia & 1 \\
Pernambuco & 1 \\
Santa Catarina & 1 \\
\hline TOTAL & 10 \\
\hline FONTE: LS - 1874-1900. &
\end{tabular}

No item "sinais particulares", as referências são as seguintes: "dois talhos de facão na mão esquerda"; "cicatriz junto a sobrancelha direita e 
outra nas costas da mão do mesmo lado"; "cicatriz de queimadura ao lado esquerdo do rosto próximo ao nariz" (cf. Anexo I, Tab. II). Alguns sentenciados usaram corrente de ferro e cinco portaram "calceta". Esta era uma argola de ferro presa ao tornozelo de ré. Dois escravos a usaram por quatro anos e um, por dois anos. Em duas sentenças, consta apenas a data em que o réu passou a usá-la. Nas outras cinco sentenças, não aparece o item "calceta".

A média do tempo real de detenção, tomando como base a data da prisão preventiva, foi de 25 anos. Notamos algumas diferenças muito pequenas entre a sentença determinada pelo juiz e o tempo real de detenção. Na sentença $n^{\circ} 1$, o réu foi condenado a 30 anos e cumpriu 29 anos e 27 dias; na sentença no 4 , o réu foi condenado a 24 anos e cumpriu 23 anos, 8 meses e 5 dias; na sentença de $n^{0} 37$, o réu foi condenado a 24 anos e cumpriu 25 anos. Percebemos a rigidez das sentenças impostas aos réus. O réu David faleceu na prisão (cf. Anexo I, Tab. II).

Com referência à profissão, era maior a incidência dos seguintes atividades: cozinheiro, jornaleiro e lavrador. Aparecem ainda as profissões de alfaiate e campeiro (cf. Anexo I, Tab. I) Cumprindo a sentença, dois escravos trabalharam nas oficinas da "Casa de Correção". Um na "oficina da palha" e outro na "sapataria".

TABELA 4

Profissão dos sentenciados

\begin{tabular}{lc}
\hline Atividądes & $\mathbb{N}^{\circ}$ de Escravos \\
\hline Cozinheiro & 4 \\
Lavrador & 2 \\
Jornaleiro & 2 \\
Alfaiate & 1 \\
Campeiro & 1 \\
\hline TOTAL & 10 \\
\hline
\end{tabular}

FONTE: LS - 1874-1900. 


\section{Notas}

1. KRAEMER, Neto. Um pouco de história. A Casa da Cadeia que vai desaparecer. Correio do Povo. Porto Alegre, 9 abril 1967.

2. José Loureiro đa Silva foi prefeito nomeado em Porto Alegre no período de 22.10 .1937 a 15.9.1943. Zero Hora. Porto Alegre, 15 novembro 1985. p.35.

3. ANDRÉ, Albero. Destruido o Cadeião, o litoral pođerá estar liberado até 1970 . Correlo do Povo. Porto Alegre, 18 maio 1967. p.12-3.

4. "Tanto pode significar o edifício, o estabelecimento prisional provido de celas para o recolhimento de presos, isoladamente, com a modalidade de pena privativa da liberdade consiste em ficar o condenado recolhido, segregado, permanentemente (dia e noite)numa cela." FRANÇA, R. Limongi. Enciclopédia Saraiva do Direlît. 5.ed. São Paulo, Saraiva, 1977. p.132.

5. "Assim se chamava a antiga embarcação a vela e a remos, em que se utilizavam frequientemente, como remadores, os condenados a trabalhos forçados. Daí porque o termo passou a significar o próprio indivíduo condenado a remar nas galés. Os condenados às galés também se diziam forçados ou grilhetas. A denominação grilheta vem do uso de se colocar no pé do condenado a grilheta, ou seja, um anel de ferro na extremidade de uma corrente do mesmo metal que se prendiam os condenados." Ibidem, p.307. 
TABELAI

Identificação geral dos sentenciados

\begin{tabular}{|c|c|c|c|c|c|c|}
\hline Número & Nome do Réu & Filiação do Réu & Nacionalidade & Naturalidade & Profissão & Grau de Instrugão \\
\hline 1 & Zefrino Amaro & Maria-Ignez & Brasileiro & Jaguarão & Campeiro & Analfabeto \\
\hline 2 & $\begin{array}{l}\text { Antônio José } \\
\text { d'Oliveira }\end{array}$ & $\begin{array}{l}\text { Joaquim Antonio } \\
\text { d'Oliveira }\end{array}$ & Brasilleiro & Bahia & Jornaleiro & Analfabeto \\
\hline 4 & Antônio & Luiz & Brasileiro & Pernambuco & Cozinheiro & Analfabeto \\
\hline 7 & Guazinio & Zulfo Fortimato & Brasileiro & RGS & Lavrador & Analfabeto \\
\hline 12 & $\begin{array}{l}\text { Caetano Francisco } \\
\text { Soares }\end{array}$ & Sertório & Brasileiro & Santa Catarina & Cozinheiro & Analfabeto \\
\hline 13 & Miguel & Noé Azevedo & Brasileiro & RGS & Alfaiate & Analfabeto \\
\hline 19 & Adão & Romão & Brasileiro & RGS & Jornaleiro & Analfabeto \\
\hline 26 & David & Eva & Brasileiro & RGS & Lavrador & Analfabeto \\
\hline 27 & Pedro de Moraes & João & Brasileiro & RGS & Cozinheiro & Analfabeto \\
\hline 37 & Nicolau & Manoel Prestes & Brasileiro & RGS & Cozinheiro & Analfabeto \\
\hline
\end{tabular}




\begin{tabular}{|c|c|c|c|c|c|c|c|c|c|c|c|c|c|c|}
\hline Número & Nome do Réu & Idade & Altaura & Cor & Cabelo & Barba & Sombrancelha & Olhos & Rosto & Boca & Testa & Orelha & Nariz & Simais Particulares \\
\hline 1 & Zeferino & 21 & 1,71 & Preto & Preto & - & - & Pardos & Comprido & - & Pequena & - & Chato & $\begin{array}{l}\text { Cicatriz junto a } \\
\text { sombrancelha direita e } \\
\text { outra nas costas da } \\
\text { mão do mesmo lado }\end{array}$ \\
\hline 2 & $\begin{array}{l}\text { Antônio José } \\
\text { d'Oliveira }\end{array}$ & 29 & 1,50 & Preto & Preto & Preta & Cerrada & Pardos & - & Grande & - & Regular & Chato & \\
\hline 4 & Antônio & 60 & - & Preto & Grizos & Grizos & - & Pardos & - & Pequena & - & - & Chato & $\begin{array}{l}\text { Dois talhos de } \\
\text { faca na măo esquerda }\end{array}$ \\
\hline 7 & Guazínio & 34 & 1,50 & Preto & Preto & Falhada & - & Pequenos & Comprido & Pequena & - & Pequenos & Chato & \\
\hline 12 & Caetano & 25 & 1,55 & Preto & Preto & Imberbe & Cerrada & - & Redondo & Regular & Regular & Regular & Rombo & \\
\hline 13 & Miguel & 23 & 1,50 & Preto & Preto & Preta & Ralas & Pretos & Preto & Regular & Regular & Regular & Afilado & \\
\hline 19 & Adão & 42 & 1,50 & Preto & Preto & Preta & Cerrada & Pardos & - & Grande & - & Regular & Chato & \\
\hline 26 & David & 45 & 1,25 & Preto & Preto & Preta & Cerrada & Pretos & Comprido & Regular & Pequena & Pequena & Chato & \\
\hline 27 & Pedro & 22 & 1,50 & Preto & - & - & Ralas & Pretos & - & Regular & Grande & Regular & Chato & \\
\hline 37 & Nicolau & 35 & 1,58 & Preto & Preto & Cerrada & Ralas & Pardos & Comprido & Regular & Grande & Regular & Chato & $\begin{array}{l}\text { Cicatriz de queimadura } \\
\text { ao lado esquerdo } \\
\text { do rosto próximo } \\
\text { ao nariz }\end{array}$ \\
\hline
\end{tabular}


Dados sobre o crime dos sentenciados

\begin{tabular}{|c|c|c|c|c|c|c|c|c|}
\hline Número & Nome do Réu & Tipo de Crime & Locall do Crime & $\begin{array}{l}\text { Data da Prisão } \\
\text { Preventiva }\end{array}$ & $\begin{array}{l}\text { Tipo de } \\
\text { Condenação }\end{array}$ & $\begin{array}{l}\text { Data de } \\
\text { Entrada Casa } \\
\text { de Corregáo }\end{array}$ & $\begin{array}{l}\text { Data da } \\
\text { Liberdade }\end{array}$ & $\begin{array}{l}\text { Tempo Real } \\
\text { de Detençäo* }\end{array}$ \\
\hline 1 & Zeferino Amaro & Homicídio & Jaguarão & 23.02 .1873 & $\begin{array}{l}30 \text { anos de } \\
\text { prisão celular }\end{array}$ & 05.02 .1874 & 20.09 .1901 & $\begin{array}{l}29 \text { anos, } 6 \text { meses } \\
\text { e } 27 \text { dias }\end{array}$ \\
\hline 2 & $\begin{array}{l}\text { Antônio José } \\
\text { d’Oliveira }\end{array}$ & Homicídio & Palmar & 23.03.1877 & $\begin{array}{l}\text { Galés perpétuas } \\
\text { depois modificada }\end{array}$ & 19.11.1878 & 06.10 .1903 & $\begin{array}{l}27 \text { anos, } 6 \text { meses } \\
\text { e } 14 \text { dias }\end{array}$ \\
\hline 4 & Antônio & Homicídio & Pelotas & 15.02 .1879 & $\begin{array}{l}24 \text { anos de } \\
\text { prisão celular }\end{array}$ & 03.05 .1881 & 20.10 .1901 & $\begin{array}{l}23 \text { anos, } 8 \text { meses } \\
\text { e } 5 \text { dias }\end{array}$ \\
\hline 7 & Guazínio & Homicídio & $\begin{array}{l}\text { Santa Vitória } \\
\text { do Palmar }\end{array}$ & 13.11.1881 & $\begin{array}{l}24 \text { anos prisão } \\
\text { celular }\end{array}$ & 30.01 .1882 & 13.11.1905 & 24 anos \\
\hline 12 & Caetano & Homicídio & Pelotas & 11.02 .1882 & $\begin{array}{l}\text { Galés perpétuas } \\
\text { depois modificada }\end{array}$ & 02.11 .1883 & 21.02.1904 & 22 anos e 11 meses \\
\hline 13 & Miguel & Homicídio & Pelotas & 06.09 .1882 & $\begin{array}{l}\text { Morte. Depois } \\
\text { modificada para } \\
\text { galés perpétuas }\end{array}$ & 02.12 .1883 & 22.01 .1907 & $\begin{array}{l}25 \text { anos, } 5 \text { meses } \\
\text { e } 16 \text { dias }\end{array}$ \\
\hline 19 & Adão & Homicídio & Pelotas & 13.02 .1882 & Galés perpétuas & 22.07 .1886 & 30.05 .1905 & $\begin{array}{l}23 \text { anos, } 2 \text { meses } \\
\text { e } 18 \text { dias }\end{array}$ \\
\hline 26 & David & Homicídio & $\begin{array}{l}\text { Sto. Antônio } \\
\text { da Patrulha }\end{array}$ & 06.11 .1886 & $\begin{array}{l}24 \text { anos prisão } \\
\text { celular }\end{array}$ & 02.12 .1887 & - & $\begin{array}{l}\text { Faleceu em } \\
25.08 .1907\end{array}$ \\
\hline 27 & Pedro de Moraes & Homicídio & $\begin{array}{l}\text { Sto. Antônio } \\
\text { da Patrulha }\end{array}$ & 01.02 .1887 & $\begin{array}{l}\text { Morte. depois } \\
\text { modificada para } \\
\text { galés perpétuas }\end{array}$ & 02.12 .1887 & 01.02.1917 & 30 anos \\
\hline 37 & Nicolau & Homicídio & Pelotas & 17.02 .1887 & $\begin{array}{l}24 \text { anos prisão } \\
\text { celular }\end{array}$ & 16.08 .1889 & 17.02 .1911 & 25 anos \\
\hline
\end{tabular}

- Cálculo feito tomando como base a data da Prisão Preventiva. 


\title{
ANEXO II \\ DECRETO № 2 DA ASSEMBLEIA PROVINCIAL DE 1835
}

\begin{abstract}
DECRETO N 2 DE 27 DE JUNHO DE 1835. ASSEMPLICIA LEGISLATIVA PROVINCIAL*
\end{abstract}

Art. 10 - Em cada um dos municípios da cidade de Porto Alegre e da Vila de São Francisco de Paula de Pelotas se estabelecerá uma Casa de Correção, que será situada, sendo preferivel, na proximidade de um rio navegável e de águas potáveis.

Art. 20 - Presidente da Província procederá imediatamente à escolha dos terrenos para as đitas Casas, e não os havendo próprios das Câmaras Municipais ou da massa dos bens da Provincia, procederá à sua aquisição por compra, regulando-se para esse fim, pelas Leis existentes.

Art. $3^{2}$ - Fará levantar a respectivas plantas e orçar as despesas da construção, atendendo que a capacidade de tais edifícios deve ser suficiente para o recolhimento e trabalho de todos os condenados da Provincia.

Art. $4^{\circ}$ - Em cada uma das referidas Casas haverá escola em que se ensinem as primeiras letras aos presos.

Art. $5^{\circ}$ - Construir-se-á em primeiro lugar a do município da cidade de Porto Alegre, marcando-se na Lei Orgânica do Orçamento a quantia necessária e só depois de concluído este edifício, se principiará o outro, excetuando-se o caso que há de indicar-se no artigo seguinte.

Art. $6^{\circ}$ - As Câmaras Municipais promoverão subscrições das quantias com cada cidadăo quiser concorrer para as mencionadas obras, e se por este meio se obtiver e realizar em cofre, soma destinada em particular à construção da segunda, que exceda ao terço da quantia orçada para o seu completo acabamento, será também logo principiada.

Art. 79 - No caso, porém, em que as quantias subscritas não se destinem especialmente à construção de uma das ditas Casas ou não excedam ao terço da despesa orçada para o seu completamento, se aplicarão na forma do artigo 5 .

Art. $8^{\circ}$ - Tanto se concluir qualquer dos edifícios de que se trata, o Presidente da Província organizará Regimento para o seu governo e administraçåo: nomeará os empregados que entender necessários e dará as mais providências indispensáveis para logo se verificar o estabelecimento: o que tudo regulará até que seja alterado pela Assembléia Legislativa Provincial a cujo conhecimento deve ser levado na sua primeira reunião.

Art. 99 - As disposições da presente Lei não embaraçam que na do Orçamento Provincial se assine anualmente qualquer soma para continuação da Casa já principiada na Vila de São Francisco de Paula, até que nela se possam acomodar dez oficinas em que os presos se apliquem ao trabalho nas oficinas de marceneiro, alfaiate, sapateiro e outros que designar a respectiva Câmara Municipal.

"Mando portanto a todas as autoridades a quem o conhecimento execução desta lei pertencer etc., etc., (a) Antônio Rodrigues Fernandes Braga. (a) Secretário do Governo Germano Francisco de Oliveira."

* In KRAEMER, Neto. Um pouco de história. A Casa da Cadeia que vai desaparecer. Correio do Povo. Porto Alegre, 9 abril 1967. 